\title{
Research on Information Channel of Climate Change Risk Perception of Shaanxi People
}

\author{
Si Wen Xue ${ }^{1,3, *,(\mathbb{D},}$, Qi Zhou ${ }^{1,2,3}$ \\ ${ }^{1}$ College of Geography and Environment, Baoji College of Arts and Sciences, Baoji 721013, China \\ ${ }^{2}$ Shaanxi Key Laboratory of Disaster Monitoring and Mechanism Simulation, Baoji College of Arts and Sciences, Baoji 721013, China \\ ${ }^{3}$ Key Research Center of Socialism with Chinese Characteristics of Shaanxi Province (Baoji Base), Baoji 721013, China
}

\section{ARTICLE INFO \\ Article History \\ Received 26 December 2020 Accepted 29 March 2021 \\ Keywords \\ Shaanxi Province \\ ANN neural network model \\ CART decision tree model \\ information channel of climate \\ change risk perception}

\begin{abstract}
We take Shaanxi Province as the research area, aiming at exploring the information channel or path of climate change risk perception of Shaanxi people. It is desirable for us to carry out information channel or path classification of climate change risk perception based on survey data involving 5493 people in Shaanxi Province. Firstly, we use a Back Propagation (BP) neural network method to fit the information path of climate change risk perception. Secondly, a decision tree model is adopted to classify information channels of climate change risk perception. The results show that 300 neurons are needed in the information channel of climate change risk perception of Shaanxi people. The first path which influences climate change risk perception of Shaanxi people is as follows: indirect perception-direct perception-indirect perception-conductive perception. The second path is indirect perception-conductive perception. The third path is as below: indirect perception-direct perception-conductive perception, which also impacts climate change risk perception. According to varying information channels or paths of climate change risk perception, the public can formulate different risk management strategies to improve the level of climate change risk perception.
\end{abstract}

(c) 2021 The Authors. Published by Atlantis Press B.V.

This is an open access article distributed under the CC BY-NC 4.0 license (http://creativecommons.org/licenses/by-nc/4.0/).

\section{INTRODUCTION}

In the context of global climate change, major natural disasters happen frequently, and risks of climate change has further increased. The public are not only the most extensive and direct disaster bearers of climate change risk events, but also the most specific executors of disaster prevention and mitigation policies [1,2]. People's ability to perceive climate change risks greatly influences their response ability. In other words, perception determines action [3]. An in-depth study of public climate change risk perception is an effective way to improve the public's ability to cope with climate change risks and reduce their vulnerability [4,5]. It also has certain practical significance for the research on national climate change risk perception and response. As scholars continue to deepen their research on climate change risk perception [6], climate change that attracts worldwide concern has gradually transformed into a scientific topic concerning the public. In this process, due to differences in climate change risk perception and knowledge between scientists and the public, the dissemination of climate change information has become an important platform for communication between scientists and the public, which directly influences whether the public can achieve favorable communication with governments and scientists. The dissemination channels and sources of climate change risk information determine whether people can accurately recognize climate change as a macro-abstract natural phenomenon, thereby influencing their attitudes and behaviors toward climate change risks.
Smith [7] held that media culture, technology and practice create the opportunity to enhance public's understanding and identification of climate change risks. Studies, such as by Maria Carmen Lemos, indicated that there is a gap between useful information understood by scientists and useful information recognized by users [8]. Hmielowski [9] also found through several studies that trust in scientists influences the use of news media, which in turn influences the understanding of global warming. Lack of information was repeatedly identified by Archie [10], among others, as an obstacle to climate change adaptation planning and implementation. Lynch [11], among others, suggested that the multiple utilization of communication tools will facilitate climate change science, as well as mitigation and adaptation policy formulation. Carmichael and Brulle [12] using structural equation models showed that although media reports play an important role, they are largely the result of elite suggestion and economic factors [12]. Julia et al. [13] noted that similar to six inter-American studies of global warming, different attitudes (the five Germanys of global warming) result in differences in understanding climate change, media use, and communication behavior. John Wiley \& Sons believed that key aspects of the communication process (including the purpose and scope of communication, the audience, the framework, the message, the messenger, the means and channels of communication, as well as the evaluation of the results and effectiveness of communication) influence climate change risk communication [14]. Moser and Dilling [15] found in their study that the lack of information and understanding explains the lack of public participation, so more information and explanations are needed to 
motivate people to take action. Lazrus and et al. [16] investigated in Florida how people express their vulnerability or activity in receiving, interpreting, and responding to hurricane risk information.

There are many types of researches on climate change policy influencing factors supported in the United States, but relatively few researches on individual climate change policy support. For illustration, Dan M. Kahan et al. [17] conducted studies in two countries (USA, $n=1500$; United Kingdom, $n=1500$ ) to test the potential value of a unique two-channel science communication strategy that combines information content ("Channel 1") with cultural significance ("Channel 2") and is chosen to promote open assessment of information from different communities.

Contrary to this hypothesis, we believed that subjects exposed to geoengineering information were concerned more about climate change risks than control conditions [17]. Xie et al. [18] used recent climate change risk perception models to predict risk perception and willingness of Australians to engage in mitigation behavior $(n=921)$, and highlighted the influence of information emotion, cognition, and sociocultural factors on climate change risk perception. Researches based on disaster event network data by Lin et al. [19] not only explored the spread of disaster information in time and space, but also investigated in detail the public natural disaster perception. Science and Technology Daily Reporter Hepeng [20] argued that compared with a large number of international counterparts, Chinese scholars paid little attention to the spread of climate change in the theme of communication. Therefore, the spread of climate change is worth an urgent and serious study in China.

At present, research on climate change risk perception channels at home and abroad has achieved certain results, but in general the most urgent concern to domestic and foreign scholars is a specific report on climate change itself: namely an in-depth analysis of how media under the joint influence of social sciences and local governments rebuild a theoretical framework and a report of China's climate change. A few scholars have analyzed the dissemination channels of global climate change risk information from the public perspective by investigating climate change perception data, thereby proposing specific information dissemination types and formulating corresponding climate change risk management strategies [21]. According to research methods, structural equation model is the widely used one, and Artificial Neural Network (ANN) neural network is frequently adopted to fight climate change risk sensing channel. The ANN neural network is a complex network structure formed by a large number of processing units. It is an information processing system established by imitating the function of brain neural network structure, and composed of sensor units with a single-layer structure [22,23]. The unit can not only make most of the calculation and complete linear function, but also simulate the signal process of human brain nerve cells based on nonlinear expression ability according to nonlinear functions. This method is close to the perception process of climate change risk information in this paper, can better simulate the human brain's perception process of climate change risk information, and is more suitable for the study of the information channel of climate change risk perception. Besides, the Classification And Regression Trees (CART) decision tree algorithm is a binomial tree model algorithm, which has the advantages of high precision and fast operation speed. It supports discrete and continuous data and can be applied to classification and regression [24]. At the same time, the CART decision tree model is suitable to classify information channels of climate change risk perception and to locate factors influencing climate change risk perception. On the other hand, Shaanxi Province suffers repeated meteorological disasters, including drought and frost, and a rainstorm to varying degrees will occur almost every year [25]. As a result, Shaanxi people are more sensitive to climate change risks and have conducted certain research [26]. Therefore, this paper will focus on the information channel of climate change risk perception, which is innovative in the field of climate communication. This paper will mainly use the ANN neural network model to simulate the information channel of climate change risk perception in Shaanxi Province, and then use the CART decision tree model to study the major information channels that influence climate change risk perception of Shaanxi people. Hopefully, the information channel classification of climate change risk perception will provide references for climate change risk management. Meanwhile, with the information channel of climate change risk perception as a breakthrough point, different policy strategies will be proposed for different information channels.

\section{MATERIALS AND METHODS}

\subsection{Overview of the Research Area}

Shaanxi Province is located in the inland central part of China, with a total area of $205,600 \mathrm{~km}^{2}$ and a population of about 36 million. There are various landforms, which can be divided into three types: the Loess Plateau in northern Shaanxi, the Guanzhong Plain and the mountains in southern Shaanxi [21]. It belongs to continental monsoon climate in general, and covers three climatic zones from south to north. Specifically speaking, northern Shaanxi, Guanzhong and southern Shaanxi belong to the temperate zone, warm temperate zone and north subtropical zone respectively. The annual precipitation is $275-1274 \mathrm{~mm}$, increasing gradually from north to south with obvious precipitation differences. The natural climates of the three landforms vary greatly. With global warming ongoing, hydrothermal conditions are enhanced, and temperature and precipitation in Shaanxi are also enhanced. Local heavy precipitation is frequent in summer and autumn. Due to unique topographic and geomorphic conditions, the frequency and intensity of geological disasters are increased. Especially in the Loess Plateau of northern Shaanxi and Qinba mountainous area of southern Shaanxi, mud-rock flows, wildfires and landslides occur frequently, causing huge loss of personnel and property. Worse still, increased rainfall and rising temperature have also led to varying degrees of drought (Figure 1).

\subsection{Data Source and the Questionnaire Content}

From July 2018 to October 2020, and based on social survey of National Natural Science Foundation of China, the public in 10 prefecture-level cities in Shaanxi Province were visited and surveyed successively. The field survey was mainly conducted in urban areas with large population increases and in rural households. The interviewees were interviewed face to face by the random survey (Figure 1). No guiding answers were given to the interviewees during the interview. In the presence of older or less educated 


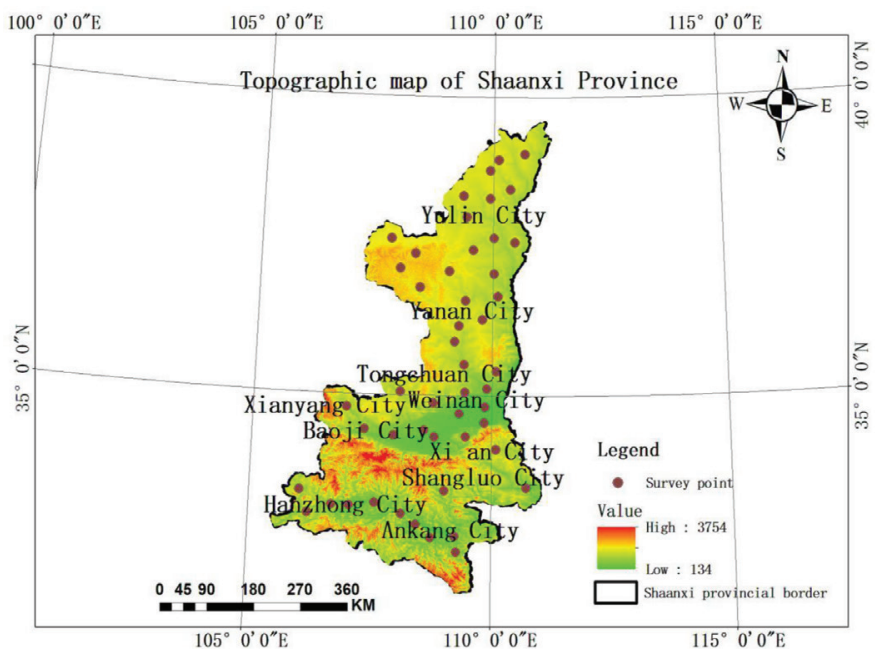

Figure 1 Topographic map of Shaanxi Province.

respondents, the interview was conducted with full explanation of the topic. This investigation method also ensured authenticity and reliability of the data and laid a foundation for the follow-up research work. To make the analysis results of the questionnaire truthful and reliable, after manually screening sample data from collected questionnaires, questionable questionnaires were screened out, such as blank questionnaires and questionnaires with inconsistent answers. Then, we entered the sample data based on the remaining questionnaires.

First, we entered the sample data on the questionnaire into the excel table, and then imported data into SPSS25.0 for subsequent investigation and analysis. Before analyzing data and results of the input questionnaire sample, first of all, options and results of questionnaire sample data were assigned. Meanwhile, some missing values and outliers in answers of questionnaire sample were checked and modified or discarded to avoid possible errors in the experimental results. After the initial manual screening, 277 questionnaires were discarded due to too many blank questions or abnormal answers. Finally, investigators got 5493 valid questionnaires, and the recovery rate of valid sample questionnaires reached $91.1 \%$. According to previous methods and experience from other experts and scholars, sample size statistics should be about 10 times of the total number of variable samples in the multi-sample size statistics and analysis of the survey.

In this paper, 35 samples of final statistical indicators and 5493 valid samples were selected, which fully met the basic requirements for experience accumulation and judgment. The statistical results of the basic characteristics of survey samples were listed in Table 1.

The main content of the questionnaire was based on the personal and family demographic characteristics of respondents, which could be divided into four parts. The first consisted of basic demographic characteristics of respondents, including sex, age, living environment, educational level and occupation, mainly used to grasp the basic information on respondents, and to facilitate exploration of the relationship between demographic characteristics
Table 1 Basic characteristics of the people surveyed

\begin{tabular}{|c|c|c|c|}
\hline Survey item & Category & Frequency & Proportion (\%) \\
\hline \multirow[t]{5}{*}{ Educational level } & $\begin{array}{l}\text { Primary school or } \\
\text { below }\end{array}$ & 650 & 11.83 \\
\hline & $\begin{array}{l}\text { Junior high } \\
\text { school-bachelor }\end{array}$ & 1174 & 21.37 \\
\hline & $\begin{array}{l}\text { High school or } \\
\text { Technical secondary } \\
\text { school }\end{array}$ & 1359 & 24.74 \\
\hline & $\begin{array}{l}\text { Undergraduate or } \\
\text { junior college }\end{array}$ & 2124 & 38.67 \\
\hline & Post-graduate & 186 & 3.39 \\
\hline \multirow[t]{6}{*}{ Monthly income } & 500 and below & 2997 & 54.56 \\
\hline & $500-1000$ & 1107 & 20.15 \\
\hline & $1001-2000$ & 946 & 17.22 \\
\hline & $2001-3000$ & 662 & 12.05 \\
\hline & $3001-5000$ & 400 & 7.28 \\
\hline & More than 5000 & 67 & 1.22 \\
\hline \multirow[t]{2}{*}{ Sex } & Man & 2631 & 47.90 \\
\hline & Woman & 2862 & 52.10 \\
\hline \multirow[t]{11}{*}{ Occupation } & $\begin{array}{l}\text { Animal husbandry } \\
\text { and fishery }\end{array}$ & 300 & 5.46 \\
\hline & $\begin{array}{l}\text { Production transpor- } \\
\text { tation work }\end{array}$ & 383 & 6.46 \\
\hline & $\begin{array}{l}\text { Service industry or } \\
\text { business }\end{array}$ & 520 & 9.47 \\
\hline & $\begin{array}{c}\text { Government } \\
\text { institution }\end{array}$ & 580 & 10.56 \\
\hline & $\begin{array}{l}\text { Professional skill } \\
\text { work }\end{array}$ & 473 & 8.61 \\
\hline & Medical staff & 350 & 6.37 \\
\hline & Teacher & 557 & 10.14 \\
\hline & Soldier & 332 & 6.04 \\
\hline & $\begin{array}{l}\text { Self-employed } \\
\text { worker }\end{array}$ & 390 & 11.47 \\
\hline & Student & 630 & 6.01 \\
\hline & Others & 978 & 17.80 \\
\hline \multirow[t]{7}{*}{ Age } & $15-25$ & 1928 & 35.10 \\
\hline & $26-36$ & 1384 & 25.20 \\
\hline & $37-47$ & 1095 & 19.93 \\
\hline & $48-58$ & 679 & 12.36 \\
\hline & $59-69$ & 307 & 5.59 \\
\hline & $70-80$ & 90 & 1.64 \\
\hline & $81-87$ & 10 & 0.18 \\
\hline
\end{tabular}

and various potential variables in the future. The second was to examine people's capacity to adapt to global climate change risks and economic conditions. The third was the subjective perception of global climate change risks, including climate change disaster perception, exposure degree perception and vulnerability perception. The fourth was composed of the public's willingness to deal with climate change risks, knowledge of climate change risks, channels to obtain information about climate change risks, and daily behaviors to cope with climate change risks. This paper mainly studied the information channels for people to deal with climate change risks. All questionnaire options followed Likert's five-level quantitative design (with some questions at four or seven levels). In this way, index options could be uniformly assigned, and the simplicity of questionnaire could also be ensured to reduce troubles. 


\subsection{Research Methods}

\subsubsection{Calculation of climate change risk perception index}

$$
G=\sum_{i}^{n} W_{i} f_{i}
$$

where $G$ was the perception index; $W_{i}$ was the weight coefficient of each factor obtained by entropy method (Table 2); $i=1,2,3$; $f_{i}$ was the corresponding degree of information acquisition; the value range of $f_{n}$ was $1-10$, and $n=1,2,3, \ldots, 5493$.

\subsubsection{ANN neural network model and CART decision tree model}

The ANN neural network model consisted of input, hidden and output layers. The number of neurons in the input layer depended on the number of independent variables. It was believed that people's information acquisition ways of climate change risks mainly

Table 2 Summary of weight calculation results by entropy method

\begin{tabular}{lccc}
\hline Item & $\begin{array}{c}\text { Information } \\
\text { entropy }\end{array}$ & $\begin{array}{c}\text { Information } \\
\text { utility value }\end{array}$ & $\begin{array}{c}\text { Weight } \\
\text { coefficient (\%) }\end{array}$ \\
\hline $\begin{array}{l}\text { B1: Are you concerned } \\
\text { about climate change } \\
\text { risks? }\end{array}$ & 0.9900 & 0.0100 & 46.53 \\
$\begin{array}{l}\text { B2: Do you think climate } \\
\text { change risks are closely } \\
\text { related to you? }\end{array}$ & 0.9940 & 0.0050 & 26.83 \\
$\begin{array}{l}\text { B3: How do you think } \\
\text { climate change risks will } \\
\text { influence your region? }\end{array}$ & 0.9940 & 0.0057 & 26.64 \\
\hline
\end{tabular}

were school education, radio and television, information from elders, friends and relatives, information from local governments, the Internet and mobile phones, previous personal experience, change of direct natural experience, popular science books and scientists, community emergency drill, and public welfare activities. Therefore, the test data on these 10 variables were used as ANN input parameters of the constitutive model (Table 3). The number of neurons in the output layer depended on the number of dependent variables, so the climate change risk perception index was chosen as an output parameter, and the number of hidden layers and neurons in each layer could be adjusted. The aim was to reduce inefficiency in the learning process and to maintain convergence rate. The CART classification tree model consisted of the root node, intermediate node and end node. The average of classified variables in final node was a predicted value $[27,28]$. This paper mainly used the CART decision tree model to transform black box model of the ANN neural network into a white box model, revealing main information channels that influenced climate change risk perception.

\section{RESULT ANALYSIS}

\subsection{Fitting Results of ANN Neural Network Model}

The ANN neural network model was used to fit public's information channels of climate change risk perception in Shaanxi Province for many times. When the number of hidden neurons was set as 100 and 200 respectively, the fitting degree $R$ of the model was smaller than 0.5 in both cases. When the number of hidden neurons was set as $300, R$ was about 0.61 , with the highest accuracy of about $53.7 \%$ (Figures 2 and 3), and the error rate was about $0.42<0.5$ (Figure 4 ), indicating that this model had a high degree

Table 3 Statistical values of influencing factors and target variables in Shaanxi

\begin{tabular}{|c|c|c|c|c|c|c|c|c|c|c|c|}
\hline Item & $\begin{array}{c}\text { School } \\
\text { education } \\
(1)\end{array}$ & $\begin{array}{c}\text { Radio and } \\
\text { television } \\
\text { (2) }\end{array}$ & $\begin{array}{l}\text { Elders, } \\
\text { relatives } \\
\text { and } \\
\text { friends (3) }\end{array}$ & $\begin{array}{c}\text { Local } \\
\text { governments } \\
(4)\end{array}$ & $\begin{array}{c}\text { Internet } \\
\text { and mobile } \\
\text { phones (5) }\end{array}$ & $\begin{array}{c}\text { Previous } \\
\text { personal } \\
\text { experience } \\
\text { (6) }\end{array}$ & $\begin{array}{c}\text { Experience } \\
\text { nature } \\
\text { changes ( } 7)\end{array}$ & $\begin{array}{l}\text { Popular } \\
\text { Science } \\
\text { Books and } \\
\text { Scientists } \\
(8)\end{array}$ & $\begin{array}{c}\text { Community } \\
\text { emergency } \\
\text { drill (9) }\end{array}$ & $\begin{array}{c}\text { Public } \\
\text { environmental } \\
\text { welfare } \\
\text { activities (10) }\end{array}$ & $\begin{array}{c}\text { Climate } \\
\text { change risk } \\
\text { perception } \\
\text { index }\end{array}$ \\
\hline Average & 4.564 & 4.914 & 4.267 & 4.883 & 4.701 & 4.421 & 4.217 & 4.333 & 3.92 & 3.905 & 2.101 \\
\hline $\begin{array}{l}\text { The } \\
\text { standard } \\
\text { deviation }\end{array}$ & 1.696 & 1.538 & 1.528 & 1.717 & 1.581 & 1.913 & 1.66 & 1.732 & 1.711 & 1.727 & 2.383 \\
\hline $\begin{array}{l}\text { Standard } \\
\text { error }\end{array}$ & 0.022 & 0.02 & 0.02 & 0.022 & 0.02 & 0.024 & 0.021 & 0.022 & 0.022 & 0.022 & 0.03 \\
\hline
\end{tabular}

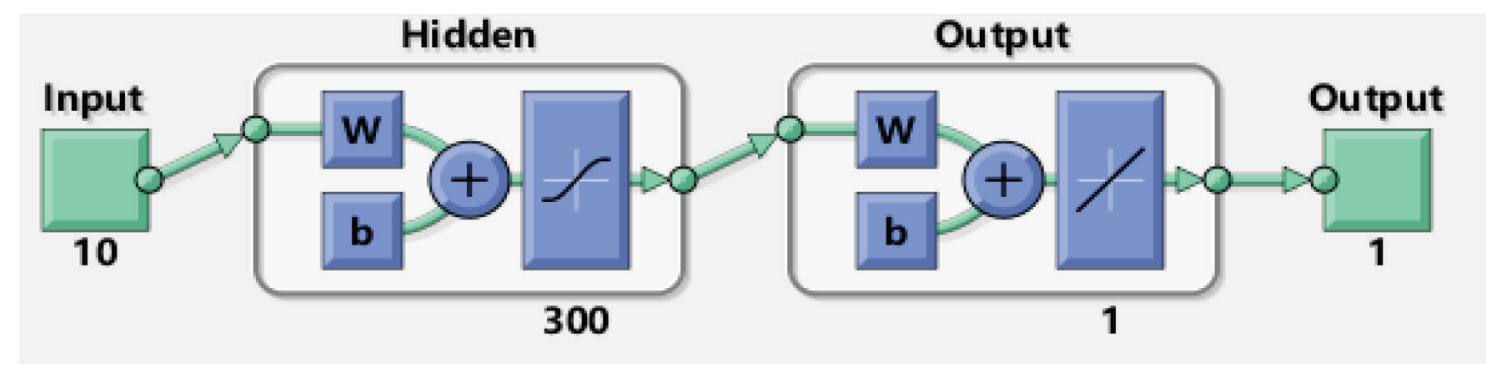

Figure 2 Fitting results of ANN neural network. 


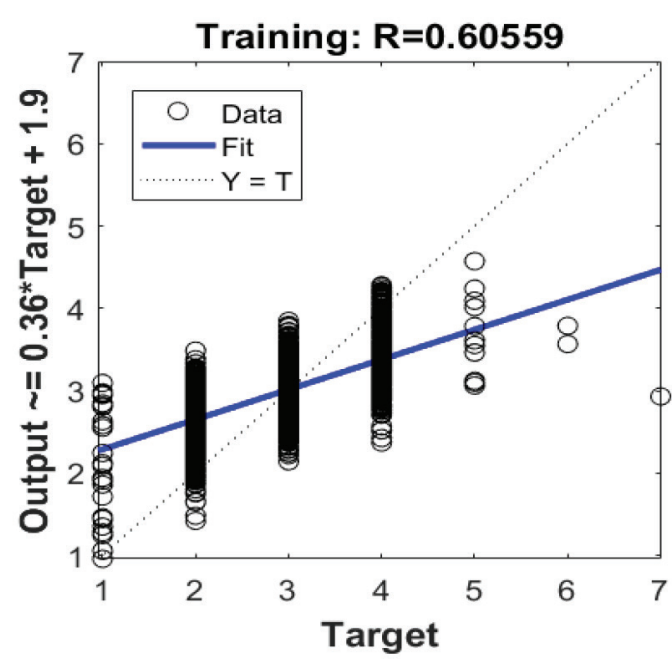

Figure 3 Fitting degree of ANN neural network.

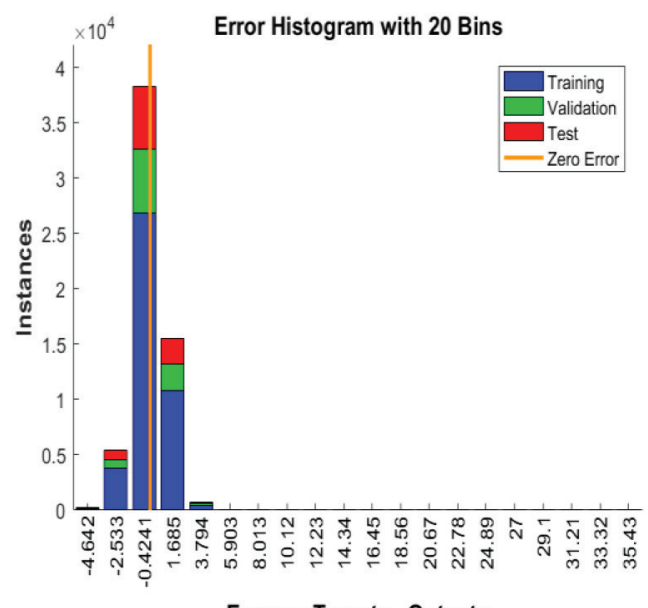

Errors $=$ Targets $\boldsymbol{-}$ Outputs

Figure 4 Error rate of ANN neural network. of fitting and could better reflect the public's climate change risk perception mechanism. This meant that when 10 pieces of climate change risk perception information worked as input, 300 neurons would be called to perceive climate change risks. There were many information channels affecting public perception of climate change risks, which needed to be analyzed in depth. However, the ANN neural network could only roughly simulate information paths of climate change risk perception, but failed to reflect detailed information channels of climate change risk perception. Therefore, to make this black-box model transparent, the CART decision tree model would be used next to calculate the information channel that influenced public's climate change risk perception.

\subsection{Research on Information Channels of Climate Change Risk Perception}

First, taking the climate change risk perception index in Formula 1 as a dependent variable and the climate change risk information acquisition mode in Table 3 as an independent variable, 2874 training samples were selected and CART decision tree model was adopted for training. As shown by the clustering results, information channels that affected public's climate change risk perception could be divided into seven categories (Figure 5), and the classified AUC value was $0.54>0.5$ (Figure 6), indicating that this model had a small error and could better reflect the information channels that affected public's climate change risk perception. Second, combining the clustering results of climate change risk perception information channels and the content of the questionnaire, the information channels of climate change risk perception could be summarized as follows (Table 4): indirect perception-conductive perception-scientific perception; indirect perception-conductive perception-scientific perception-local government informationconductive perception; indirect perception-conductive perceptionscientific perception-local government notification; indirect perception-direct perception-third party notification-conductive perception; indirect perception-direct perception; indirect perception-conductive perception-government notification; and indirect

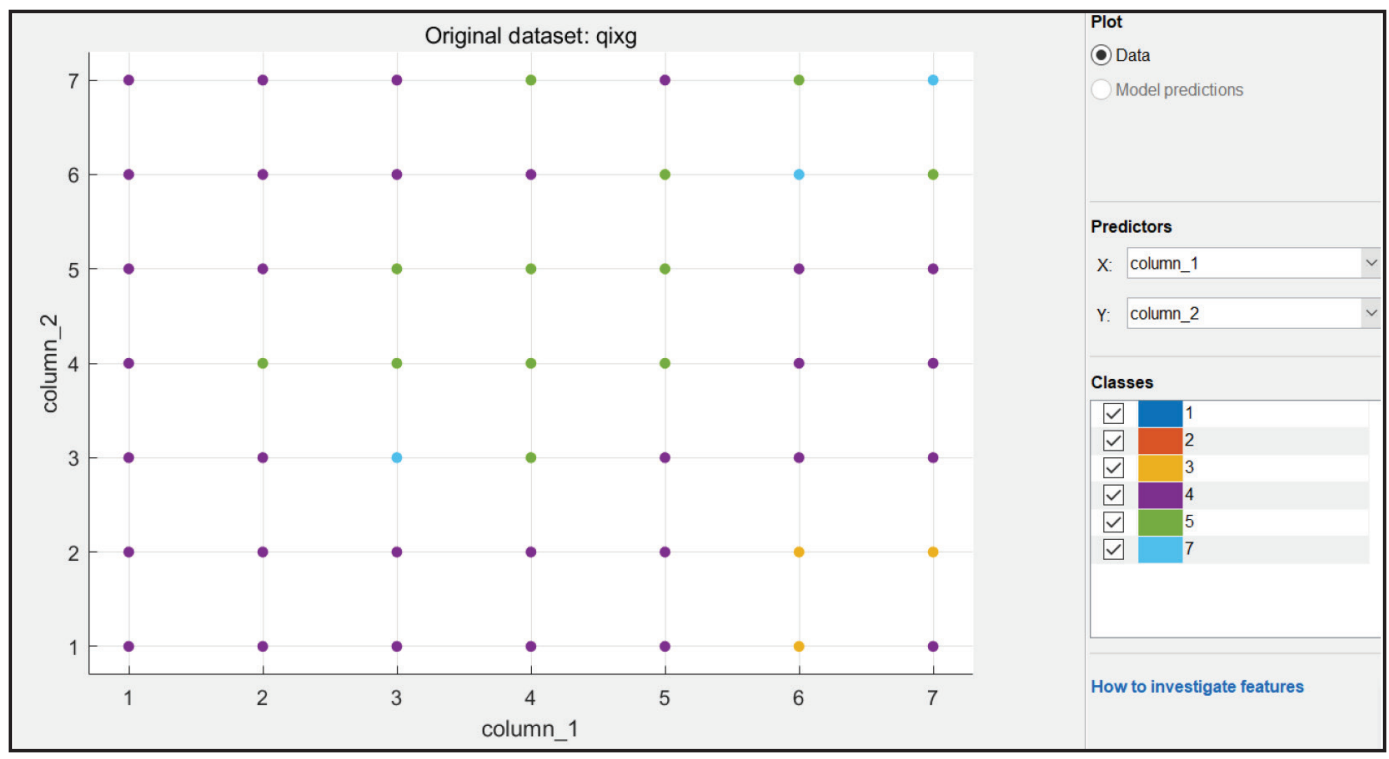

Figure 5 Path classification results of climate change risk perception. 


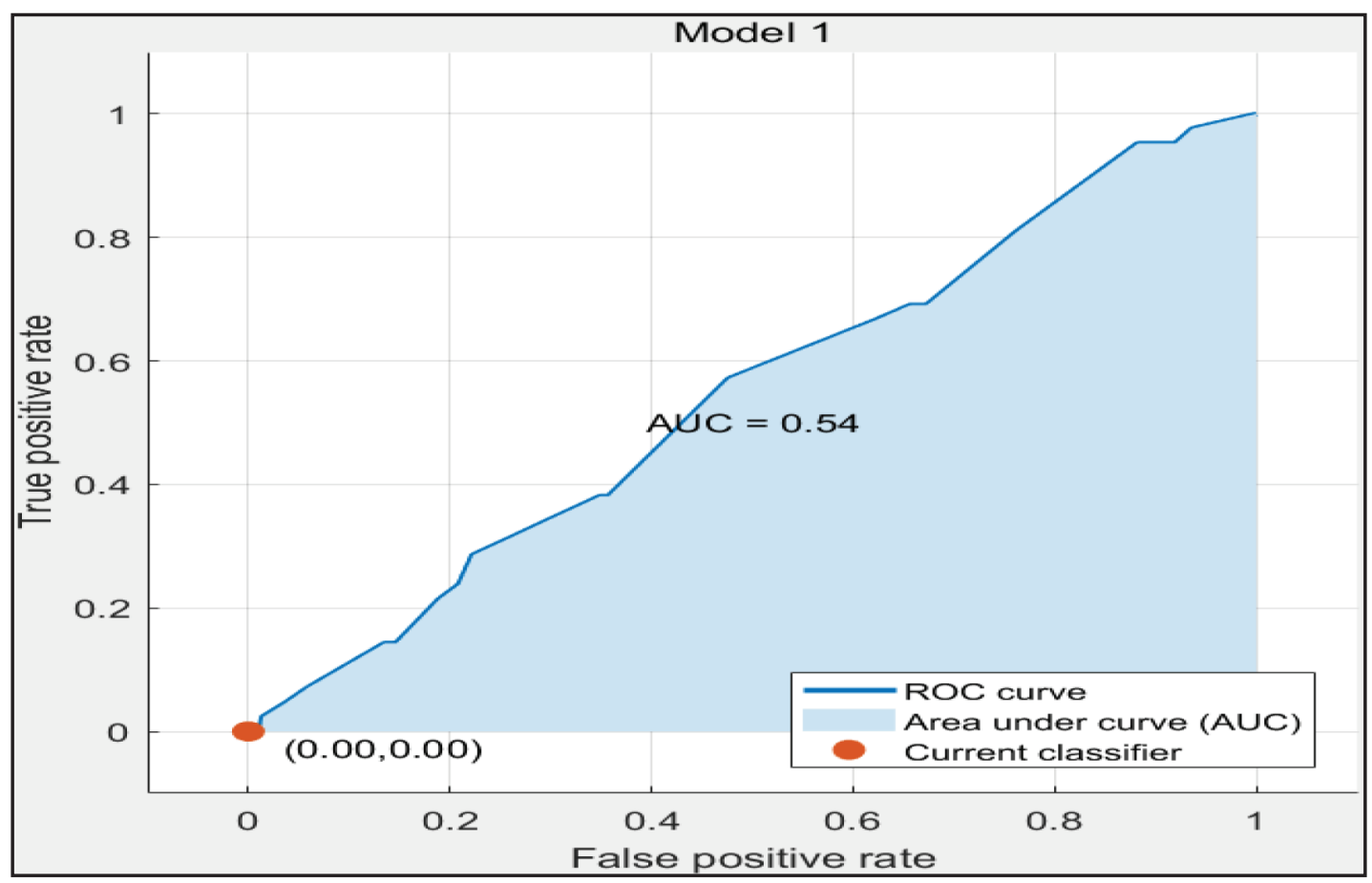

Figure 6 ROC curve.

Table 4 Classification of information channels of climate change risk perception

\begin{tabular}{ll}
\hline Path & Category of information channel \\
\hline 1 and 2 & $\begin{array}{c}\text { Indirect perception-conductive perception-scientific } \\
\text { perception (5.981\%) }\end{array}$ \\
3 & $\begin{array}{c}\text { Indirect perception-conductive perception-scientific } \\
\text { perception-local government notification-conductive } \\
\text { perception (10.420\%) }\end{array}$ \\
4 & $\begin{array}{c}\text { Indirect perception-conductive perception-scientific } \\
\text { perception-local government notification (1.276\%) }\end{array}$ \\
5 and 6 & $\begin{array}{c}\text { Indirect perception-direct perception-third party } \\
\text { notification-conductive perception (39.022\%) }\end{array}$ \\
8 & $\begin{array}{c}\text { Indirect perception-direct perception (10.260\%) } \\
\text { Indirect perception-conductive perception-government } \\
\text { notification (4.625) }\end{array}$ \\
9 & Indirect perception-conductive perception (28.416\%) \\
\hline
\end{tabular}

perception-conductive perception. Third, as shown in Table 4, indirect perception-conductive perception-scientific perception; indirect perception-conductive perception-scientific perceptionlocal government information-conductive perception; indirect perception-conductive perception-scientific perception-local government notification; indirect perception-direct perception-third party notification-conductive perception; indirect perceptiondirect perception; indirect perception-conductive perceptiongovernment notification; and indirect perception-conductive perception paths accounted for $5.981 \%, 10.420 \%, 1.276 \%, 39.022 \%$, $10.260 \%, 4.625 \%$ and $28.416 \%$ respectively. This indicated that the information channel that most affected climate change risk perception was indirect perception-direct perception-third party notification-conductive perception, accounting for $39.022 \%$; the second was indirect perception-conductive perception, taking up $28.416 \%$; and the third was indirect perception-conductive perceptionscientific perception-local government information-conductive perception, accounting for $10.420 \%$ (Figure 7 ). This suggested that real knowledge came from practice, and that the channel of conductive perception was an important part of the process of people's climate change risk perception. Only by continuously personally experiencing or practicing climate change risk information, such as third-party notification, scientist notification, government notification could people's climate change risk perception be enhanced.

Based on the above three typical information channels of climate change risk perception in Shaanxi Province, the public could make the following adjustments in managing climate change risks. As for the indirect perception-direct perception-third party notificationconductive perception path, we had better strengthen the accuracy of radio and television notification and scientific nature of popular science books. For indirect perception-conductive perception path, we should accumulate more practical experience and increase the number of direct experiences. For indirect perception-conductive perception-scientific perception-local government informationconductive perception path, the public could organize more risk emergency drills to improve people's conductive perception level, and then improve people's climate change risk perception. Also, we were supposed to ensure the accuracy of people's second notification or information acquisition, to avoid interruption of communication, thus reducing people's perception of climate change risks. Finally, it was necessary to avoid perception bias and to achieve the accuracy of terminal recovery or the intermediate information conduction by reducing the interference of third-party notification.

\section{DISCUSSION}

The ANN neural network method could be used to promptly determine the number of information channels of people's climate 


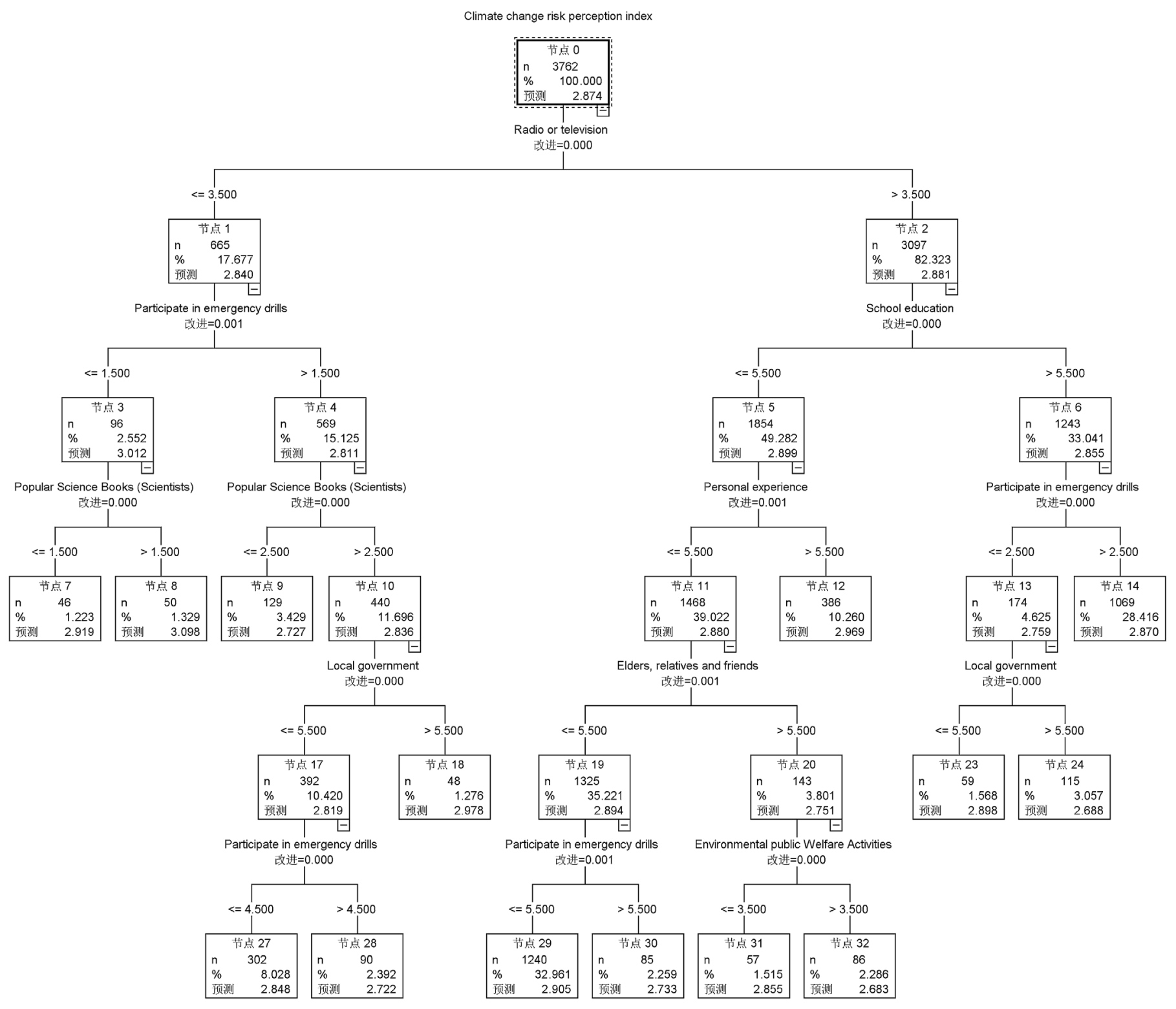

Figure 7 Information channels of climate change risk perception.

change risk perception, because it was more objective than the traditional structural equation model in reflecting brain's processing of climate change risk information. The finding was consistent with the principle established by Guoru et al. [29], who constructed a multi-layer perception model to analyze the factors that affected farmers' climate change risk perception, when minimizing the prediction error of the target variable. On the basis of the ANN neural network method, it was concluded that when the maximum fitting degree of ANN neural network model was 0.53, there were 300 hidden neurons in the risk perception process of climate change in Shaanxi Province, which was similar to the research results obtained by related scholars. However, the ANN neural network method was a black-box model, and the intermediate path was not clear. Therefore, we used the CART decision tree model to explore the main information channels that influenced public's climate change risk perception in Shaanxi Province. There were seven main information channels of climate change risk perception. This may be related to the brain's self-protection mechanism that processed up to seven pieces of information to protect the body from harm, which agreed with the conclusion by relevant scholars that there were five information channels of climate change risk perception [30]. The training accuracy of the CART decision tree model reached 54\%, and the indirect perception-direct perceptionthird party notification-conductive perception path (39.022\%) had the greatest influence on perception of climate change risks. The second followed the indirect perception-conductive perception path (28.416\%). Finally, the indirect perception-conductive perception-scientific perception-local government notificationconductive perception path also had a major impact on climate change risk perception $(10.420 \%)$. In short, the conductive perception link was at the end of the climate change risk perception information channel, which was consistent with related studies believing that the conductive perception of community emergency drills had the greatest impact on the climate change risk perception index [31]. However, the first-end of climate change risk perception information channels was the indirect perception method 
in most cases. This showed that mass media and communication exerted a greater impact on climate change risk perception, which was similar to the research results by some scholars [32-36]. These references confirmed the above conclusions in terms of mass media information, daily climate change risk events and agricultural activities, and the public's trust in information sources.

The innovations of this paper were mainly reflected in the following three aspects. First, based on the CART decision tree model, the paper not only located the main information channels influencing climate change risk perception, but also clearly classified information channels of climate change risk perception into seven categories. Second, on the one hand, we created more innovative methods than the traditional weighting method or linear regression [37]; on the other hand, we made a breakthrough in content. Ofoegbu and New [38] believed that information flow and exchange through organizational collaboration networks had a limited effect on improving farmers' knowledge about climate risks, impacts and available risk response options. Ponce de Leon [39] studied the effect of information on the evacuation of Typhoon Haiyan in the Philippines, and found that according to the media and researchers, people did not have enough information about the storm, or did not understand the information given to them, and therefore did not evacuate, and that participants from different locations in the same municipality understood warning information differently. Kalafatis et al. [40] provided five sources of climate change information, leading interviewees to reflect on their experiences and to gain new knowledge from them; each interviewee described a reflection system, and increased attention to these tailored reflection systems offered a path to understanding how experiential learning could most effectively enhance climate change decision support. The above-mentioned researches on the information paths of climate change risk perception have focused on the influence of information on climate change risk perception and on the theoretical level of climate change risk perception channel, but there are few researches on the internal mechanism and specific path or information channel of climate change risk perception. Therefore, the study of the information channel simulation of climate change risk perception and internal mechanism in this paper was innovative to a certain extent, and could reasonably reveal the principle of climate change risk perception. In other words, most scholars have failed to comprehensively consider factors that affect climate change risk perception from the perspective of the dissemination channels of climate change risk information. And it was indicated that only through repeated practice and exercise could we enhance the climate change risk perception. Third, the above conclusions had certain practical significance and application value. People could take different measures to deal with climate change risks, according to different information channels of climate change risk perception in varied regions.

\section{CONCLUSION}

(1) There were 300 hidden neurons in the risk perception process of climate change in Shaanxi Province, showing that a lot of information channels affected climate change risk perception in Shaanxi Province.

(2) The indirect perception-direct perception-third party notification-conductive perception path $(39.022 \%)$ had the greatest influence on the perception of climate change risks. The second followed the indirect perception-conductive perception path $(28.416 \%)$. Finally, the indirect perception-conductive perception-scientific perception-local government notificationconductive perception path also had a huge impact on climate change risk perception (10.420\%).

(3) We could formulate different strategies aimed at different information channels of climate change risk perception to improve people's climate change risk perception level. As for the indirect perception-direct perception-third party notificationconductive perception path, it was necessary to strengthen the accuracy of radio and television notification and popular science books. For the indirect perception-conductive perception path, it was desirable to accumulate more direct experiences. For the indirect perception-conductive perceptionscientific perception-local government notification-conductive perception path, the public should participate in risk emergency drills actively and frequently.

\section{CONFLICTS OF INTEREST}

The authors declare they have no conflicts of interest.

\section{AUTHORS' CONTRIBUTION}

SWX wrote all the contents of the manuscript and paid for the retouches. QZ was responsible for only searching some references of the manuscript.

\section{ACKNOWLEDGMENTS}

This work is supported by the National Natural Science Foundation of China for "Regional Climate Change Risk Perception and Response" (41771215). The authors appreciate the time and effort spent by the editors and reviewers in providing constructive comments which have helped to improve the manuscript.

\section{REFERENCES}

[1] Yifan J. Differences in people's cognition and response to earthquake disasters in Tibetan areas. Qinghai province, China: Qinghai Normal University; 2015.

[2] Guiwu S, Zongjin M, Ruojia W, Yue W, Boyang D, Shuwei Z, et al. The characteristics of people's cognition and response to earthquake disaster in Wenchuan earthquake areas and the significance of publicity and education on disaster reduction - a case study of Deyang City, Sichuan Province. Seismogeology 2008;30:877-94.

[3] Yifan J, Benyong W, Guiwu S, Haifeng Z, Lei S, Yang W. Preliminary analysis on the cognitive characteristics of earthquake disaster for government officials in Yushu, Qinghai. Disaster Sci 2015;30:229-34.

[4] Wei D. Research on disaster risk perception of residents in Guangzhou. Lanzhou city, China: Lanzhou University; 2014.

[5] Koresawa A. Government's response to the Great East Japan Earthquake and Tsunami. J Disaster Res 2012;7:517-27. 
[6] Yushuang W. Research on the coupling relationship between public perception of climate change and adaptation behavior in northern Shaanxi. Northeast Normal University; 2015.

[7] Smith J. Dangerous news: media decision making about climate change risk. Risk Anal 2005;25:1471-82.

[8] Lemos MC, Kirchhoff CJ, Ramprasad V. Narrowing the climate information usability gap. Nature Clim Change 2012;2:789-94.

[9] Hmielowski JD, Feldman L, Myers TA, Leiserowitz A, Maibach E. An attack on science? Media use, trust in scientists, and perceptions of global warming. Public Underst Sci 2014;23:866-83.

[10] Archie KM, Dilling L, Milford JB, Pampel FC. Unpacking the 'information barrier': comparing perspectives on information as a barrier to climate change adaptation in the interior mountain West. J Environ Manage 2014;133:397-410.

[11] Lynch AH, Tryhorn L, Abramson R. Working at the boundary: facilitating interdisciplinarity in climate change adaptation research. Bull Am Meteorol Soc 2008;89:169-79.

[12] Carmichael JT, Brulle RJ. Elite cues, media coverage, and public concern: an integrated path analysis of public opinion on climate change, 2001-2013. Environ Polit 2017;26:232-52.

[13] Metag J, Füchslin T, Schäfer MS. Global warming's five Germanys: a typology of Germans' views on climate change and patterns of media use and information. Public Underst Sci 2017;26:434-51.

[14] Moser SC. Communicating climate change: history, challenges, process and future directions. WIREs Clim Change 2010;1:31-53.

[15] Bolton RE. Americans and climate change: closing the gap between science and action. J Plan Edu Res 2006;26:123-5.

[16] Lazrus H, Morrow BH, Morss RE, Lazo JK. Vulnerability beyond stereotypes: context and agency in hurricane risk communication. Weather Clim Soc 2012;4:103-9.

[17] Kahan DM, Jenkins-Smith H, Tarantola T, Silva CL, Braman D. Geoengineering and climate change polarization: testing a two-channel model of science communication. Ann Am Acad Polit Soc Sci 2015;658:192-222.

[18] Xie B, Brewer MB, Hayes BK, McDonald RI, Newell BR. Predicting climate change risk perception and willingness to act. J Environ Psychol 2019;65:101331.

[19] Lin GS, Qi Z, Mingjie L, Yanjun W, Sharecropper S, Guannan C, et al. Spatio-temporal differentiation and influencing factors of new media users' disaster cognition and response - a case study of Shouguang flood in Shandong. Sci Disasters 2020;35:210-16.

[20] Hepeng J. Global warming, science communication and public participation - analysis of the communication of climate change technology in China. Popul Sci Res 2007;39-45.

[21] Yujie L. Information source, channel and content - research on climate communication strategies of Chinese people based on investigation. Int Media 2013;35:67-83.

[22] Gardner MW, Dorling SR. Artificial neural networks (the multilayer perceptron) - a review of applications in the atmospheric sciences. Atmos Environ 1998;32:2627-36.

[23] Rosenblatt F. The perceptron: a probabilistic model for information storage and organization in the brain. Psychol Rev 1958;65:386-408.
[24] Tao L. Analysis of enterprise communication activity based on CART decision tree. Netw Secur Technol Appl 2020;53-4.

[25] Kegang W. China meteorological disasters of Shaanxi Province. China: Meteorological Press; 2005.

[26] Yo-chuang Y, Qi Z, Chang-yan W. Temporal and spatial variation of people's climate change perception in northern Shaanxi. J Northwest Univ (Nat Sci Ed) 2011;41:134-8.

[27] Yuan-hui R, Wen G, Wei-qiang C, Yue-hong M. Research on economical and intensive benefits of construction land based on analytic hierarchy process - taking Shangqiu City as an example. Chinese Agric Sci Bull 2016;32:87-91.

[28] Chunxin L, Tianwei L. Decision support and analysis technique for CART algorithm based on decision tree. Comput Sci 2004;31:44-6.

[29] Guoru W, Xingmin S, Lifan S, Lu W, Huanjuan L. The diversity of farmers' perception and adaptation behaviors of climate change in dry farming areas. J Shaanxi Norm Univ (Nat Sci Ed) 2020;48: $116-24$.

[30] Siwen X, Qi Z. Research on the information channel of climate change risk perception in northern Shaanxi based on CART decision tree. Henan Sci 2020;38:1641-9.

[31] Bigl B. Stop the frack! Exploring the media's portrayal of the social representation of an anti-fracking protest at the Baltic Sea. Environ Commun 2020;14:271-86.

[32] Bo C. Research on the impact of climate change media information framework on public risk perception and behavior will. Nanjing City, China: Nanjing University; 2019.

[33] Lingyun W. The impact of media sources and information balance on climate change risk perception: research based on experiments. Zhejiang University; 2018.

[34] Fleming K, Abad J, Booth L, Schueller L, Baills A, Scolobig A, et al. The use of serious games in engaging stakeholders for disaster risk reduction, management and climate change adaption information elicitation. Int J Disaster Risk Reduction 2020;49: 101669

[35] Hesam M, Roshan G, Grab SW, Shabahrami AR. Comparative assessment of farmers' perceptions on drought impacts: the case of a coastal lowland versus adjoining mountain foreland region of northern Iran. Theor Appl Climatol 2021;143:489-503.

[36] Vainio A, Paloniemi R, Varho V. Weighing the risks of nuclear energy and climate change: trust in different information sources, perceived risks, and willingness to pay for alternatives to nuclear power. Risk Anal 2017;37:557-69.

[37] Xingmin S. Research progress on public perception and adaptation to climate change. Water Soil Conserv Bull 2016;36:25.

[38] Ofoegbu C, New M. The role of farmers and organizational networks in climate information communication: the case of Ghana. Int J Clim Change Strat Manage 2021;13:19-34.

[39] Ponce de Leon IZ. Of warnings and waiting: an examination of the path of information for two communities hit by Typhoon Haiyan. J Risk Res 2020;23:598-612.

[40] Kalafatis SE, Neosh J, Libarkin JC, Whyte KP, Caldwell C. Experiential learning processes informing climate change decision support. Weather Clim Soc 2019;11:681-94. 